\title{
EXPRESSÃO IMUNO-HISTOQUÍMICA DA VIMENTINA E DO HHF-35 EM FIBROMA DE CÉLULAS GIGANTES, HIPERPLASIA FIBROSA E FIBROMA DA MUCOSA ORAL
}

\author{
IMMUNOHISTOCHEMICAL EXPRESSION OF VIMENTIN AND HHF-35 IN \\ GIANT CELL FIBROMA, FIBROUS HYPERPLASIA AND FIBROMA OF THE \\ ORAL MUCOSA
}

\author{
Márcia Cristina da Costa MIGUEL \\ Doutoranda do Programa de Pós-Graduação em Patologia Oral da UFRN. \\ Emanuel Savio de Souza ANDRADE \\ Doutorando do Programa de Pós-Graduação em Patologia Oral da UFRN. Prof. de Patologia Bucal da FOP-UPE. \\ Danielle Albuquerque Pires ROCHA \\ Bolsista do PIBIC-CNPq/UFRN. \\ Roseana de Almeida FREITAS \\ Professora Doutora da Disciplina de Patologia Oral e do Programa de Pós-Graduação em Patologia Oral da UFRN. \\ Lélia Batista de SOUZA \\ Professora Doutora da Disciplina de Patologia Oral e do Programa de Pós-Graduação em Patologia Oral da UFRN.
}

\section{INTRODUÇÃO}

O fibroma de células gigantes (FCG) é considerado por alguns autores como uma lesão não neoplásica benigna descrita inicialmente por Weathers, Callihan em $1974^{5,12}$, representando um crescimento reativo focal da mucosa oral ${ }^{9,10}$. Esta lesão representa $5 \%$ de todas as proliferações fibrosas submetidas à biópsia ${ }^{11}$.

Usualmente, é observada em pacientes jovens ${ }^{8}$ sendo mais freqüente nas três primeiras décadas de vida, apresentando-se como lesões assintomáticas, papilíferas ou lobuladas, pediculadas, medindo menos que $1 \mathrm{~cm}$ de diâmetro ${ }^{6}$, acometendo principalmente a gengiva inferior e o ápice e borda lateral da língua ${ }^{12}$. Neville, et $\mathrm{al}^{11}$ afirmam ainda, que há uma leve predileção pelo sexo feminino.

Microscopicamente, o FCG exibe características peculiares, sendo composto por um tecido conjuntivo fibroso usualmente arranjado frouxamente com ausência de inflamação e revestido por epitélio pavimentoso estratificado hiperplásico, sendo a presença de células gigantes mono, bi ou multinucleadas, fusiformes ou estreladas e localizadas predominantemente na lâmina própria papilar, a sua 
principal característica histopatológica ${ }^{2,5,8}$.

Estas células gigantes mono, bi ou multinucleadas não são exclusivas do FCG, sendo detectadas também em outras lesões fibrosas como fibroma ungueal, angiofibroma acral e fibroblastoma desmoplásico ${ }^{5}$ e mais especificamente nas hiperplasias fibrosas e fibromas da cavidade oral ${ }^{15}$. A natureza desta população celular vem sendo amplamente discutida por diversos pesquisadores ${ }^{5,8,12}$, porém ainda não foi completamente estabelecida.

A hiperplasia fibrosa é considerada um crescimento reativo focal que aparece circundando as margens ou bordas de próteses totais ou parciais removíveis mal adaptadas, estando relacionada com a irritação crônica causada por estas e, por forças oblíquas resultantes de desajustes oclusais ${ }^{13}$. Microscopicamente, caracterizase por um epitélio pavimentoso estratificado freqüentemente hiperplásico, ceratinizado, alternando áreas de hiperceratose e paraceratose. $\mathrm{O}$ tecido conjuntivo varia de acordo com o estágio de desenvolvimento da lesão, apresentando-se como um tecido de granulação nas lesões jovens e com um conjuntivo denso e fibroso nas lesões mais antigas, exibindo usualmente um infiltrado de células inflamatórias crônicas ${ }^{14}$.

O fibroma representa um tumor de natureza conjuntiva originário de proliferação de fibroblastos ${ }^{3}$ sendo considerado por Shafer, Hine, Levy ${ }^{17}$ a neoplasia de tecido mole mais comum da cavidade oral, porém Neville, et al. ${ }^{11}$ afirmam que há dúvidas quanto a esta lesão representar um neoplasma verdadeiro; na maioria das situações talvez seja uma hiperplasia reacional do tecido conjuntivo fibroso em resposta a irritação local ou a um trauma, apresentando-se como uma massa nodular de tecido conjuntivo denso e colagenizado, coberto por um epitélio pavimentoso estratificado, geralmente atrófico.

O fibroma de células gigantes, a hiperplasia fibrosa e o fibroma constituem algumas das mais freqüentes lesões fibrosas dos tecidos moles orais. Com o intuito de investigar a origem destas células e se estas têm a mesma origem nas três entidades citadas, este trabalho propôs-se a realizar um estudo imuno-histoquímico utilizando dois marcadores celulares (vimentina e actina de músculo) comparando os achados nas lesões estudadas.

\section{MATERIAL E MÉTODOS}

Foram selecionados 10 casos de fibroma de células gigantes, 10 de hiperplasia fibrosa e 10 de fibroma oriundos dos arquivos do Serviço de Anatomia
Patológica da Disciplina de Patologia Oral do Departamento de Odontologia da Universidade Federal do Rio Grande do Norte. De acordo com os dados obtidos nas fichas clínicas, dos 10 casos de fibroma de células gigantes, 5 ocorreram na mucosa jugal, 4 na gengiva e 1 em língua, com o tamanho variando de 0,7 a $3 \mathrm{~cm}$ com uma média de $1,3 \mathrm{~cm}$. Dos casos de hiperplasia fibrosa, 6 acometeram o rebordo alveolar superior, 3 o sulco vestibular e 1 o ápice da língua, cujas dimensões variaram de 0,2 a $3,5 \mathrm{~cm}$ com uma média de $1,6 \mathrm{~cm}$. Quanto aos fibromas, 6 casos ocorreram na mucosa jugal, 2 no lábio inferior e 2 na gengiva medindo de 0,6 a $2,5 \mathrm{~cm}$ e média de $1,3 \mathrm{~cm}$. Na seleção dos casos utilizou-se os parâmetros microscópicos definidos na literatura para cada lesão $0^{2,5,8,11,13,14,17}$. A partir dos espécimes emblocados em parafina foram obtidos cortes de $3 \mathrm{~mm}$ de espessura, os quais posteriormente foram submetidos à técnica imuno-histoquímica pelo método da estreptavidina-biotina. Os anticorpos primários utilizados foram anti-actina de músculo (clone HHF35 ${ }^{1,2}$ - DAKO, Corporation Carpinteria, USA) com uma diluição de 1:100 e incubação por 60 minutos e anti-vimentina (clone V9- DAKO A/S, Dinamarca) diluída a 1:50 e incubado por 120 minutos. Os cortes foram expostos ao anticorpo secundário e o complexo revelador diluídos a 1:100. A diaminobenzidina a $0,03 \%$ foi usada como cromógeno para revelação da reação e a contra-coloração foi feita com hematoxilina de Mayer.

Cada caso, foi então analisado ao microscópio de luz (Olympus CH30RF200), com aumento de 400X, por dois examinadores em horários diferentes, previamente treinados. Para avaliação da marcação imuno-histoquímica, considerou-se como positiva a célula gigante estrelada que exibiu qualquer marcação para os anticorpos, representada pela cor acastanhada, independente da intensidade de coloração, ou seja, o suficiente para diferenciação entre células positivas e negativas. Analisou-se separadamente o componente celular da lâmina própria papilar e lâmina própria reticular, utilizando-se como parâmetro a presença ou ausência de células marcadas. Os vasos sangüíneos e os fibroblastos presentes nos espécimes foram usados como controle interno da reação para o HHF-35 e a vimentina, respectivamente.

\section{RESULTADOS}

A vimentina foi expressa no citoplasma das numerosas células gigantes estreladas encontradas na lâmina própria papilar na maioria dos casos de fibroma 
de células gigantes (Tabela 1 e Figura 1 ). $\mathrm{Na}$ hiperplasia fibrosa e no fibroma, 50 e $60 \%$ dos casos respectivamente, exibiram imunomarcação para vimentina (Tabela 1 e Figuras 2 e 3), a qual foi observada nas poucas células gigantes presentes nestas lesões. Na lâmina própria reticular a expressão da vimentina diferiu entre as lesões, com um maior número de casos positivos no fibroma de células gigantes (Tabela 2).

Em relação ao HHF-35, a grande maioria dos casos foi negativa para este anticorpo (Figura 4) observandose marcação apenas em células na lâmina própria papilar do fibroma de células gigantes e do fibroma (Tabela 3).

\section{DISCUSSÃO}

O fibroma de células gigantes foi identificado como uma entidade específica baseando-se nas suas características clínicas, distribuição anatômica, potencial de crescimento limitado e aspecto histológico distinto ${ }^{18}$, onde as células gigantes estreladas representam a sua principal característica. Contudo, esta mesma célula tem sido relatada em outras lesões fibrosas orais, como hiperplasia fibrosa, o fibroma, a papila retrocanina e em uma variedade de lesões localizadas em outras partes do corpo, parecendo fazer parte do espectro normal de resposta tecidual a injúrias ${ }^{12}$.

Vários estudos sugeriram diferentes origens para as células gigantes estreladas como a linhagem melanocítica ${ }^{6,18}$, porém estudos mais recentes descartam essa possibilidade, visto que essas células mostraram-se negativas para anticorpos contra a proteína $\mathrm{S}-100^{8,12}$. As células de Langerhans foram cogitadas como representando estas células gigantes, mas foram excluídas devido ao fato dos grânulos de Birbeck não serem identificados nestas células em estudos ultraestruturais ${ }^{4}$.

Uma derivação da linhagem monocítica macrofágica também tem sido sugerida para as células gigantes do fibroma de células gigantes, uma vez que Regezi, et al. ${ }^{15}$ encontraram positividade variável para antiquimiotripsina e HLA-DR, demonstrando que estas células poderiam representar células

TABELA 1- Expressão imuno-histoquímica da vimentina nas células gigantes na lâmina própria papilar de fibroma de células gigantes, hiperplasia fibrosa e fibroma da mucosa oral. Natal-RN, 2002

\begin{tabular}{lccc}
\hline LESÕES & AUSENTE & PRESENTE & TOTAL \\
\hline Fibroma de Células Gigantes & 1 & 9 & 10 \\
Hiperplasia Fibrosa & 5 & 5 & 10 \\
Fibroma & 4 & 6 & 10 \\
\hline
\end{tabular}

TABELA 2- Expressão imuno-histoquímica da vimentina nas células gigantes na lâmina própria reticular de fibroma de células gigantes, hiperplasia fibrosa e fibroma da mucosa oral. Natal-RN, 2002

\begin{tabular}{lccc}
\hline LESÕES & AUSENTE & PRESENTE & TOTAL \\
\hline Fibroma de Células Gigantes & 3 & 7 & 10 \\
Hiperplasia Fibrosa & 8 & 2 & 10 \\
Fibroma & 7 & 3 & 10 \\
\hline
\end{tabular}

TABELA 3- Expressão imuno-histoquímica do HHF35 em células gigantes na lâmina própria papilar de fibroma de células gigantes, hiperplasia fibrosa e fibroma da mucosa oral. Natal-RN, 2002

\begin{tabular}{llcl}
\hline LESÕES & AUSENTE & PRESENTE & TOTAL \\
\hline Fibroma de Células Gigantes & 8 & 2 & 10 \\
Hiperplasia Fibrosa & 10 & 0 & 10 \\
Fibroma & 9 & 1 & 10
\end{tabular}




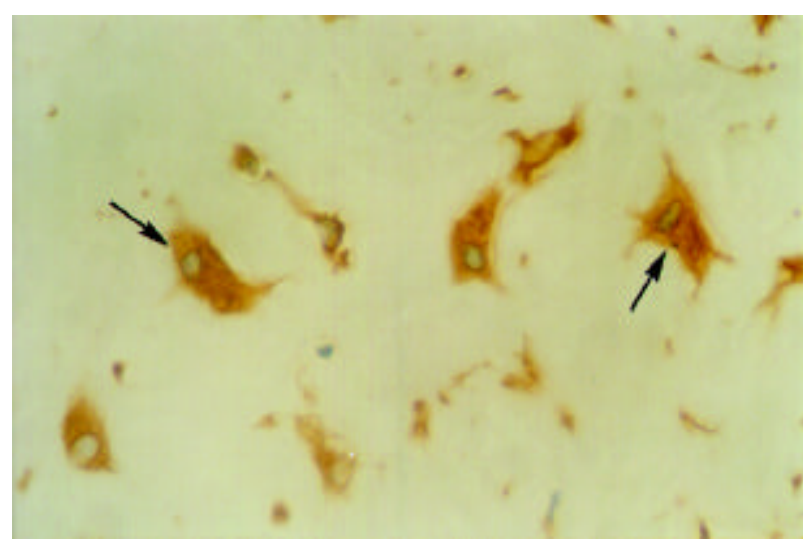

FIGURA 1- Marcação positiva para a vimentina nas células gigantes estreladas (setas) do fibroma de células gigantes (estreptavidina-biotina, 400X)

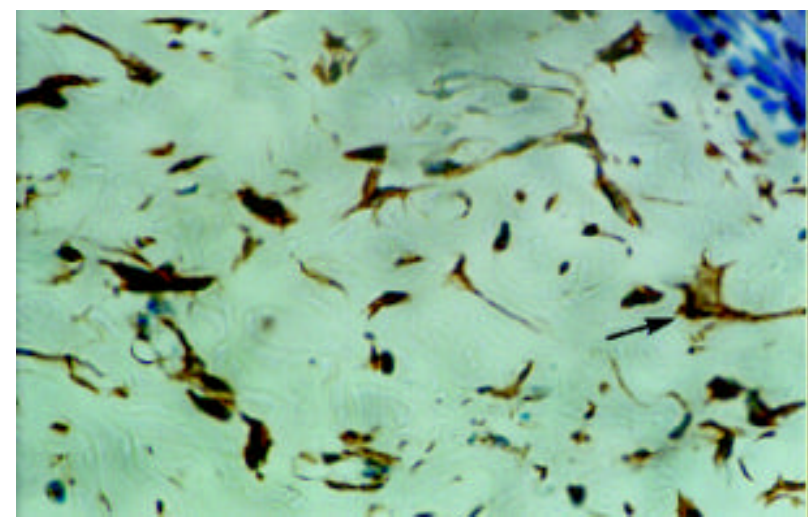

FIGURA 3- Marcação imuno-histoquímica para a vimentina visualizada em célula gigante estrelada (seta) do fibroma (estreptavidina-biotina, 400X)

mesenquimais primitivas com potencial de diferenciação macrofágica ou fibroblástica, embora outros autores como Odell, Lock, Lombardi ${ }^{12}$ e Magnusson, Rasmusson ${ }^{8}$ discordem desta possibilidade, pois não detectaram em seus estudos, imunorreação destas células para o CD-68 e o LCA (antígeno leucocitário comum) respectivamente, antígenos estes normalmente observados em células da linhagem monocítica macrofágica.

Tem sido considerada também a possibilidade destas células derivarem dos dendrócitos localizados na mucosa. Estudos de Odell, Lock, Lombardi ${ }^{12}$ encontraram positividade para o fator XIIIa em 2 dos 16 casos por eles pesquisados, enquanto Campos, Gomez ${ }^{5}$ observaram em seu estudo negatividade para o fator XIIIa em todos os 9 casos de fibromas de células gigantes, o que, segundo eles excluiria a possibilidade

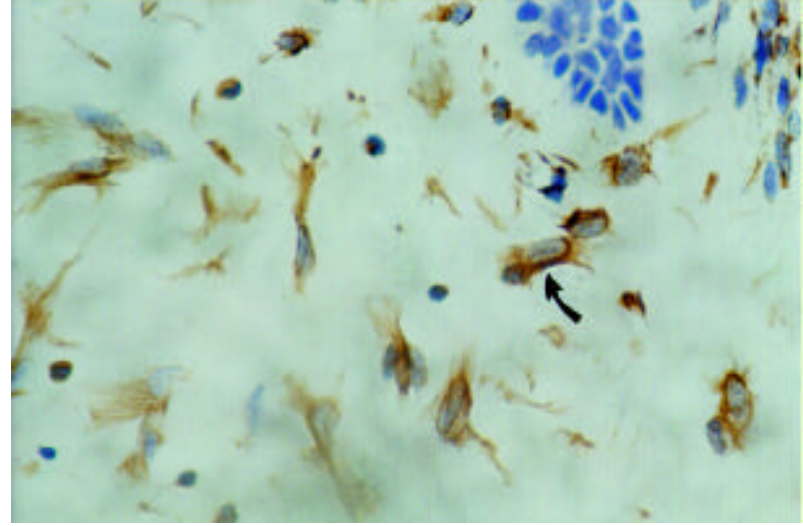

FIGURA 2- Imunorreatividade à vimentina em célula gigante estrelada (seta) observada na hiperplasia fibrosa (estreptavidina-biotina, 400X)

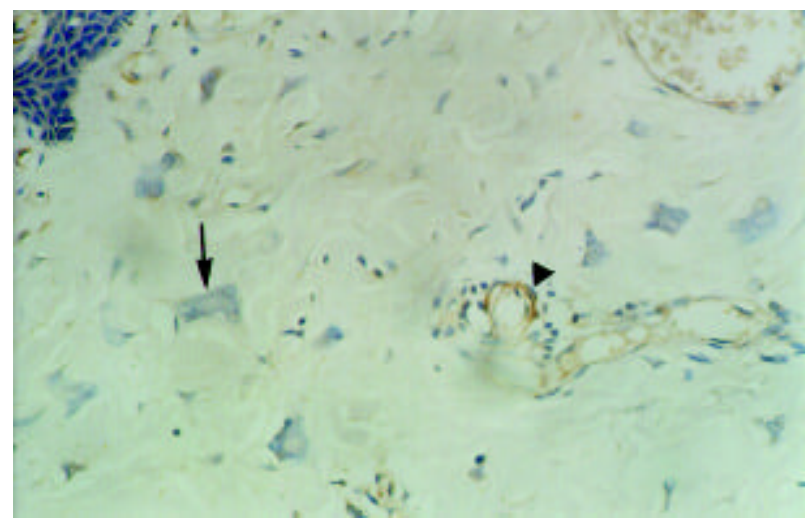

FIGURA 4- Ausência de imunomarcação para o HHF-35 nas células gigantes estreladas do fibroma de células gigantes (seta). Observar positividade em parede de vasos (cabeça de seta) como controle interno da reação (estreptavidina-biotina, 200X)

do fenótipo dendrocítico.

Neste estudo, utilizamos a vimentina e o HHF-35, para verificação da possível origem fibroblástica e miofibroblástica, respectivamente. Os resultados evidenciaram que na lâmina própria papilar do fibroma de células gigantes, as células gigantes mono, bi ou multinucleadas expressaram a vimentina na maioria dos casos, estando ausente em apenas um caso, a despeito de reação positiva no controle interno. Já nas hiperplasias fibrosas e fibromas também houve marcação, porém esta foi evidenciada em 50 e $60 \%$ dos casos, respectivamente. Na lâmina própria reticular, observou-se marcação em $70 \%$ dos casos de fibroma de células gigantes, uma vez que estas células também são encontradas em quantidade variável nesta localização, fato este não observado nos casos de hiperplasia fibrosa e fibroma, onde as células gigantes, 
quando presentes, estão em número reduzido, o que explica o baixo percentual de marcação positiva, ou seja, $20 \%$ para hiperplasia fibrosa e $30 \%$ para o fibroma nos casos aqui estudados.

Nossos achados imuno-histoquímicos com a vimentina no fibroma de células gigantes, concordam com os da literatura, onde Odell, Lock, Lombardi ${ }^{12}$ encontraram positividade nas células gigantes estreladas para a vimentina e prolil 4-hidroxilase nos 16 casos de fibroma de células gigantes por eles estudados, o que segundo os autores, sugere um fenótipo fibroblástico funcional. Magnusson, Rasmusson $^{8}$ e Campos, Gomez ${ }^{5}$ também evidenciaram imunorreação para a vimentina em todos os casos de fibroma de células gigantes estudados.

Nas hiperplasias fibrosas e fibromas, a marcação imuno-histoquímica para a vimentina nas células gigantes estreladas foi observada em um número menor de casos, quando comparada ao fibroma de células gigantes, o que pode ser atribuído ao fato de que algumas células identificadas pela coloração de rotina como as células gigantes pesquisadas, representassem na verdade, outro tipo celular como dendrócitos ou células de Langerhans, cuja presença ocasional é esperada nessas entidades. Segundo Regezi, et al. ${ }^{16}$ os dendrócitos são residentes normais da submucosa, sendo encontrados na lâmina própria, espaço perivascular e tecido conjuntivo intersticial.

Em todas as lesões estudadas, as células endoteliais mostraram-se imunorreativas para a vimentina o que está de acordo com as afirmações de Alberts, et al. ${ }^{1}$ que relatam que a vimentina, dentre as proteínas dos filamentos intermediários, é a mais amplamente distribuída, ocorrendo em fibroblastos, células endoteliais, leucócitos e outras células de origem mesodérmica. Odell, Lock, Lombardi ${ }^{12}$ também obtiveram resultados semelhantes em relação às células endoteliais em seus estudos com fibroma de células gigantes.

Quanto aos nossos achados imuno-histoquímicos para o HHF-35, embora dois casos de fibroma de células gigantes e um caso de fibroma tenham exibido marcação imuno-histoquímica para este anticorpo, esta foi detectada em poucas células, o que sugere que tais células imunorreativas correspondam a verdadeiros miofibroblastos, os quais podem estar presentes em tecidos sofrendo injúrias, fato facilmente observado na cavidade oral. Neste sentido, Lombardi, Morgan ${ }^{7}$ relataram que os miofibroblastos são encontrados em várias condições patológicas da cavidade oral, tais como, fascite nodular, histiocitoma fibroso maligno, hiperplasia gengival, cápsulas de cistos odontogênicos e não odontogênicos, além de terem detectado em seu estudo a presença de células imunopositivas para aactina de músculo liso em espécimes de gengiva marginal.

Estudos de Odell, Lock, Lombardi ${ }^{12}$ e Campos, $\mathrm{Gomez}^{5}$, nos quais foi utilizada a a-actina de músculo liso para detecção de fenótipo miofibroblástico no componente celular de fibromas de células gigantes, não detectaram imunopositividade para este marcador. Tais resultados levaram os autores a excluírem a possibilidade de uma origem miofibroblástica para esta lesão.

Considerando-se que na grande maioria dos casos de fibroma de células gigantes do presente estudo, as células gigantes estreladas exibiram imunomarcação para a vimentina e foram negativas para a actina de músculo (HHF-35), a hipótese mais plausível é que estas células realmente derivem de uma linhagem fibroblástica. Já em 1974, Weathers, Campbell ${ }^{19}$ sugeriram que estas células gigantes observadas no fibroma de células gigantes eram formadas pelo fusionamento de células mononucleares semelhantes a fibroblastos. Mighell, Robinson, Hume ${ }^{10}$ em 1996 também sugeriram que tais células realmente resultem da fusão de fibroblastos, o que justificaria a presença das mesmas em outras lesões fibrosas, o que pôde ser observado nesse estudo tanto em hiperplasias fibrosas quanto em fibromas.

\section{CONCLUSÃO}

Diante dos resultados, verificou-se que as células gigantes mono, bi ou multinucleadas estreladas, observadas nas lesões estudadas expressaram predominantemente a vimentina, sugerindo uma possível natureza fibroblástica, sem contudo determinar tal origem. Além disso, não evidenciou-se uma participação significativa de miofibroblastos na etiopatogenia destas lesões baseando-se nos achados para o HHF-35. Estudos utilizando outros marcadores para uma completa caracterização fenotípica destas células são necessários para elucidar sua histogênese.

\section{ABSTRACT}

The giant cell fibroma, fibrous hyperplasia and fibroma are the most frequent fibrous oral lesions, sharing clinical and histopathological features. The purpose of this study was to investigate the immunoreactivity of the large stellate-shaped mononuclear and multinucleated cells, reported as the most characteristic histological feature of the giant cell 
fibroma but present occasionally in fibrous hyperplasia and fibroma, for the antibodies vimentin and HHF-35 in order to detect phenotypical characteristic of these cells. The results showed in the most of cases positive staining for vimentin, suggesting a fibroblast phenotype for these cells.

UNITERMS: Giant cell fibroma; Fibrous hyperplasia; Fibroma; Oral mucosa; Immunohistochemistry.

\section{AGRADECIMENTOS}

À CAPES e CNPq que apoiaram parcialmente esta pesquisa.

\section{REFERÊNCIAS BIBLIOGRÁFICAS}

1- Alberts B, Bray D, Lewis J, Raff M, Roberts K, Watson JD. O citoesqueleto. In: Alberts B, Bray D, Lewis J, Raff M, Roberts K, Watson JD. Biologia molecular da célula. 3. ed. Porto Alegre: Artes Médicas; 1997. p. 787-861.

2- Albuquerque Jr RLC, Medeiros KBM, Pereira Pinto L, Souza LB. Fibroma de células gigantes: estudo histomorfológico de 21 casos e discussão dos conceitos atuais. RBO 2001; 58:122-8.

3- Araújo NS, Araújo VC. Neoplasias benignas e malignas. In: Araújo NS, Araújo VC. Patologia Bucal. São Paulo: Artes Médicas; 1984. p. 117-41.

4- Bakos LH. The giant cell fibroma: a review of 116 cases. Am J Dent 1992; 5: 32-5.

5- Campos E, Gomez RS. Immunohistochemical Study of Giant Cell Fibroma. Braz Dent J 1999; 10:89-92.

6- Houston GD. The giant cell fibroma: a review of 464 cases. Oral Surg Oral Med Oral Pathol 1982; 53:582-7.

7- Lombardi T, Morgan PR. Immunohistochemical characterisation of odontogenic cysts with mesenchymal and myofilament markers. J Oral Pathol Med 1995; 24:170-6.

8- Magnusson BC, Rasmusson LG. The giant cell fibroma: a review of 103 cases with immunohistochemical findings. Acta Odontol Scand 1995; 53: 293-6.

9- Mighell AJ, Robinson PA, Hume WJ. Immunolocalisation of tenascin-C in focal reactive overgrowths of oral mucosa. J Oral Pathol Med 1996; 25: 163-9.

10- Mighell AJ, Robinson, PA, Hume WJ. PCNA and Ki-67 immunoreactivity in multinucleated cells of giant cell fibroma and peripheral giant cells granuloma. J Oral Pathol Med 1996; 25:1939.
11- Neville BW, Damm DD, Allen CM, Bouquot JE. Tumores dos tecidos moles. In: Neville BW, Damm DD, Allen CM, Bouquot JE. Patologia Oral e Maxilofacial. Rio de Janeiro: Guanabara Koogan; 1998. p.353-404.

12- Odell E, Lock C, Lombardi T. Phenotypic characterisation of stellate and giant cells in giant cell fibroma by immunocytochemistry. J Oral Pathol Med 1994; 23: 284-7.

13- Pinto-Coelho CM, Silva-Sousa YTC, Daré AMZ, Cardoso CM. Avaliação preliminar das lesões da mucosa bucal associadas ao uso de prótese removível. Rev Odont Univ Ribeirão Preto 2000; 3:3-9.

14- Pinto-Coelho CM, Zucoloto, S. Hiperplasia fibro-epitelial inflamatória da cavidade oral. Revista APCD 1998; 52: 383-7.

15- Regezi JA, Zarbo RJ, Tomich CE, Lloyd RV, Coutney RM, Crissman JD. Immunoprofile of benign and malignant fibrohistiocytic tumors. J Oral Pathol 1987; 16:260-5.

16- Regezi JA, Zarbo RJ, Daniels TE, Greenspan JS. Oral traumatic granuloma. Characterization of the cellular infiltrate. Oral Surg Oral Med Oral Pathol 1993; 75:723-7.

17- Shafer WG, Hine MK, Levy BM. Tumores benignos e malignos da cavidade bucal. In: Shafer WG, Hine MK, Levy BM. Tratado de patologia bucal. 4 ed. Rio de Janeiro: Editora Guanabara , 1987. p.80-212.

18- Weathers DR, Callihan MD. Giant-cell fibroma. Oral Surg Oral Med Oral Pathol 1974; 37:374-84.

19- Weathers DR, Campbell WG. Ultraestructure of the giant-cell fibroma of the oral mucosa. Oral Surg Oral Med Oral Pathol 1974; 38:550-61.

Endereço do autor correspondente:

Prof. Dra. Lélia Batista de Souza

Universidade Federal do Rio Grande do Norte

Faculdade de Odontologia

Programa de Pós-Graduação em Patologia Oral

Av. Sen. Salgado Filho, 1787

Lagoa Nova Natal-RN Brasil

CEP- 59056-000 Fone: (0xx84) 215-4138

e-mail: leliasouza@dod.ufrn.br 